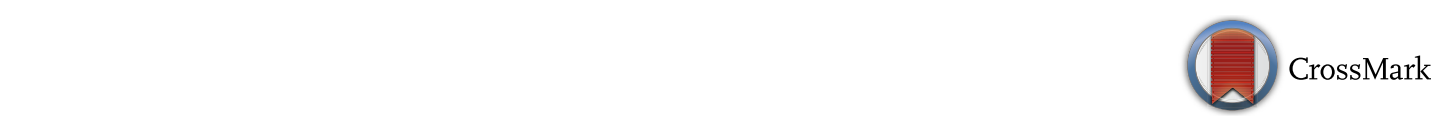

\title{
Elastic Thickness Determination from on-orbit GOCE Data and CRUST1.0
}

\author{
Mehdi Eshagh $^{1}$ and Martin Pitoñák ${ }^{2}$
}

\begin{abstract}
Elastic thickness $\left(T_{\mathrm{e}}\right)$ is a parameter representing the lithospheric strength with respect to the loading. Those places, having large values of elastic thickness, flexes less. In this paper, the on-orbit measured gravitational gradients of the Gravity field and steady-state Ocean Circulation Explorer (GOCE) mission are used for determining the elastic thickness over Africa. A forward computational method is developed based on the Vening MeineszMoritz (VMM) and flexural theories of isostasy to find a mathematical relation between the second-order derivative of the Earth's gravity field measured by the GOCE satellite and mechanical properties of the lithosphere. The loading of topography and bathymetry, sediments and crystalline masses are computed from CRUST1.0, in addition to estimates of laterally-variable density of the upper mantle, Young's modulus and Poisson's ratio. The second-order radial derivatives of the gravitational potential are synthesised from the crustal model and different a priori values of elastic thickness to find which one matches the GOCE on-orbit gradient. This method is developed in terms of spherical harmonics and performed at any point along the GOCE orbit without using any planar approximation. Our map of $T_{\mathrm{e}}$ over Africa shows that the intra-continental hotspots and volcanoes, such as Ahaggar, Tibesti, Darfur, Cameroon volcanic line and Libya are connected by corridors of low $T_{\mathrm{e}}$. The high values of $T_{\mathrm{e}}$ are mainly associated with the cratonic areas of Congo, Chad and the Western African basin.
\end{abstract}

Key words: Elastic thickness, Forward modelling, GOCE gravitational gradients, Isostasy.

\section{Introduction}

The Gravity field and steady-state Ocean Circulation Explorer (GOCE, Drinkwater et al. 2003) was the first satellite mission, which measured the secondorder directional derivatives of the gravitational

1 Department of Engineering Science, University West, Trollhättan, Sweden. E-mail: mehdi.eshagh@hv.se

2 NTIS-The New Technologies for the Information Society, Faculty of Applied Sciences, University of West Bohemia, Technická 8, 30614 Pilsen, Czech Republic. E-mail: pitonakm@ntis.zcu.cz potential or gravitational gradients, with a uniform quality and a near-global coverage. The primary goal of this mission was to model the Earth's static gravitational field and map the ocean circulation. Now, we use the GOCE on-orbit data, namely EGG_TRF_2 product (Gruber et al. 2010), and not global gravitational models (GGMs), to determine the elastic thickness $\left(T_{\mathrm{e}}\right)$ of the Earth's lithosphere, which is a novel application. $T_{\mathrm{e}}$ is one of the mechanical properties of the lithosphere showing the lithospheric strength with respect to the loads. Lithosphere with a large $T_{\mathrm{e}}$ resists more against the loads and flexes less. Our approach can be developed simply for any other type of gravitational potential field gradient.

According to Airy's (1855) theory of isostasy, the mountains have roots beneath. It is assumed that the Earth's crust is constructed by vertical columns with the same density and lateral thickness, the taller columns thrust more into the upper mantle than the shorter ones. In other words, the mountains have roots beneath and the geometry of their roots changes so as do topographic heights, but in the opposite direction. Heiskanen (1938) has modelled this principle mathematically, and since then this principle is known as the Airy-Heiskanen (AH) principle. The drawback of this theory was that the crust cannot be considered to be formed from separate discrete columns, and consequently the compensation of the mountainous masses will be strictly local. Therefore, the shear stress amongst the columns should be considered to have a regional compensation support. Vening Meinesz (1931) considered this problem from a different prospective and considered the lithosphere as a solid continuum medium, on which the topographic masses act as the loads flexing it downwards. This leads to what Vening Meinesz meant for regional compensation. In other words, the shear 
stresses amongst the columns are considered to make the compensation of the masses regional. According to this theory, the Moho discontinuity, the boundary between the crust and upper mantle, will not be as deep as the one derived from the AH principle. An extensive review on lithospheric flexure is found in Watts (2001).

Isostasy can also be studied using gravity data. The isostatic gravity anomaly is defined as the difference between the gravity anomaly and the interaction of the attractions of the topographic and compensating masses at the geoid (Heiskanen and Moritz 1967, p.138). This principle can be used for determining the Moho interface or density contrast between the crust and upper mantle. Moritz (1990) mathematically modelled this idea in the spherical domain based on the assumption that the isostatic gravity anomaly should be zero, and he called it the Vening Meinesz method; see also Sjöberg (2009).

However, the original idea of Vening Meinesz (1931) was based on loading theory. In this way, the mechanical properties of the lithosphere, like rigidity, elastic thickness $\left(T_{\mathrm{e}}\right)$, Young's modulus and Poisson's ratio are considered instead of gravity data. Eshagh (2016a, b) compared the Vening MeineszMoritz (VMM) and the flexural models of isostasy (Vening Meinesz 1931; Watts 2001, p. 186) theoretically and showed that both deliver similar models of Moho.

Vening Meinesz (1931) assumed that the lithosphere is an elastic shell with the thickness $T_{\mathrm{e}}$, which can be determined according to the coherence methods (Forsyth 1985) comparing gravity data to topographic heights. The most common method for computing elastic thickness is done in the Fourier transform (e.g., Watts 2001, p. 195). So far, many efforts have been made for determining $T_{\mathrm{e}}$, and here we mention some of them. Calmant et al. (1990) investigated $T_{\mathrm{e}}$ and its relation with the age of the oceanic lithosphere. $T_{\mathrm{e}}$ in the Marquesas and Society Islands was determined by Filmer et al. (1993). Audet and Mareschal (2004) estimated $T_{\mathrm{e}}$ over Canada, Gómez-Ortiz et al. (2005) in the Iberian Peninsula, Burov and Diament (1995) studied the meaning of the effective $T_{\mathrm{e}}$ of the continental lithosphere. Spatial variations of the flexural rigidity over South America and the Alpine-Carpathian arc and its relation to gravity anomalies by forward modelling approach were investigated by Stewart and Watts (1997). The usefulness of free-air and Bouguer gravity anomalies for the $T_{\mathrm{e}}$ determination over continents was presented by McKenzie and Fairhead (1997). Johnsson et al. (2000) studied the Martian lithospheric loading. They used the method presented by Turcotte et al. (1981), which combines Jeffrey's (1976) method for Moho determination and flexural theory. A method based on inverse modelling was presented and applied by Braitenberg et al. (2002) over the eastern Alps. A review of the inverse spectral methods for determination of $T_{\mathrm{e}}$ was published by Kirby (2014). A similar study over the Arabian plate has been performed by Chen et al. (2015). Tesauro et al. (2017) continued the study further by considering temperature, composition and strain rates of the lithosphere. The admittance method was applied by McGovern et al. (2002) for Martian elastic thickness determination. Ojeda and Whitman (2002) used the coherence approach to the $T_{\mathrm{e}}$ determination in the northern South America and Swain and Kirby (2003a) applied the same method in Australia. McKenzie (2010) compared the coherence and admittance methods. McKenzie (2003) modelled $T_{\mathrm{e}}$ considering the effects of the internal loads. Swain and Kirby (2003b) used the Forsyth (1985) method for estimating $T_{\mathrm{e}}$ in Australia. Tassara (2005) reviewed the flexural analysis along the Andean margin. Jordan and Watts (2005) used both forward and non-spectral inverse gravity modelling techniques to determine the $T_{\mathrm{e}}$ structure of the IndiaEurasia collisional system. Tassara et al. (2007) used a wavelet formulation of the classical spectral isostatic analysis for the same purpose over South America and its surrounding plates. Similar studies over Fennoscandia, South America and Africa were performed by Pérez-Gussinyé et al. (2004, 2007, 2009). Kalnins and Watts (2009) studied the spatial variation of $T_{\mathrm{e}}$ in the western Pacific Ocean. Galán and Casallas (2010) used satellitederived gravity data to determine $T_{\mathrm{e}}$ over the Colombian Andes based on the admittance method. Tesauro et al. (2013) presented a global model for $T_{\mathrm{e}}$ considering the variations of the Young modulus within the lithosphere. Abbaszadeh et al. (2013) and Zamani et al. (2014) determined an elastic thickness 
for Iran. Eshagh (2018) has presented a method for elastic thickness determination in a spherical harmonic domain and applied it over South America and Eshagh et al. (2018) over Asia.

There are some studies claiming the use of satellite data for determination of $T_{\mathrm{e}}$, but in reality a GGM, derived from a satellite mission, was used for this purpose. In fact, this GGM is used for generating gravity anomalies and later on the admittance or coherence approach is implied for estimating $T_{\mathrm{e}}$. Therefore, any GGM can be used for such purpose, and it is not very much related to the satellite data. Here, we develop a novel method, which employs the on-orbit satellite gradiometric data of GOCE directly and not a GGM. We will use the CRUST1.0 model (Laske et al. 2013) for incorporating the contributions of topographic and bathymetric, sediments, crustal crystalline masses, lateral variations of upper mantle density, Young's modulus and Poisson's ratio. The effect of the long wavelength portion of the gradiometric data, which comes mainly from the deep mantle is reduced from the GOCE data and finally $T_{\mathrm{e}}$ will be estimated based on our forward computational method over Africa. We chose this area because only one study was dealing with $T_{\mathrm{e}}$ determination over the whole African continent. This is the work of PérezGussinyé et al. (2009) from coherence analysis of topography and Bouguer anomaly data. Djomani et al. (1995) studied an effective $T_{\mathrm{e}}$ in west central Africa and Moctar et al. (1996) in South Africa and not over the whole continent. Our new $T_{\mathrm{e}}$ map can present alternative interpretable information for geologists or geophysicists. However, the main purpose of this paper is to present a method for $T_{\mathrm{e}}$ modelling from the GOCE on-orbit data rather than a geophysical interpretation.

\section{The VMM and Flexural Theories of Isostasy}

The Moho flexure can be computed by two different approaches: the VMM method, which is in fact a gravimetric approach, and the flexural method, which uses $T_{\mathrm{e}}$ of the lithosphere. Eshagh (2017) presented the following formula for determining the Moho flexure model based on the VMM theory:

$$
\begin{aligned}
& \Delta T^{\mathrm{VMM}}=\frac{1}{4 \pi G \Delta \rho} \sum_{n=0}^{\infty}\left(\frac{2 n+1}{n+1}\right) \beta_{n} \\
& \quad \times \sum_{m=-n}^{n}\left(\delta g_{n m}^{\mathrm{TB}}+\delta g_{n m}^{\mathrm{Sed}}+\delta g_{n m}^{\mathrm{Cry}}-\delta g_{n m}\right) Y_{n m}(\theta, \lambda),
\end{aligned}
$$

where $G$ is the Newtonian gravitational constant, $\Delta \rho$ is the density contrast between the crust and upper mantle. Symbols $\delta g_{n}, \delta g_{n}^{\mathrm{TB}}, \delta g_{n}^{\text {Sed }}$ and $\delta g_{n}^{\text {Cry }}$ are, respectively, the Laplace coefficients of the gravity disturbance $(\delta g)$, and effects of topographic/bathymetric, sediment and crustal crystalline effects on $\delta g$, $Y_{n m}(\theta, \lambda)$ represents the fully-normalised spherical harmonic coefficients of degree $n$ and order $m$ with arguments of spherical co-latitude $\theta$ and longitude $\lambda$. The parameter $\beta_{n}$ is (Eshagh 2017):

$$
\beta_{n}=\left\{\begin{array}{l}
\left(1-(n+2) \frac{T_{0}}{2 R}\right)^{-1} \text { continents } \\
1 \text { oceans }
\end{array}\right.
$$

$R$ is the mean radius of the spherical Earth and $T_{0}$ the mean Moho depth, which is normally taken from seismic models.

According to Vening Meinesz (1931) topographic masses push the lithospheric shell downwards by their weights. The Moho flexure in this case can be described mathematically by (see Eshagh 2016b):

$$
\Delta T^{\mathrm{Flex}}=\sum_{n=0}^{\infty} C_{n} \sum_{m=-n}^{n}(\bar{K})_{n m} Y_{n m}(\theta, \lambda),
$$

where $(\bar{K})_{n}$ are the Laplace coefficients of

$$
\bar{K}=\bar{\rho} H+\delta \rho^{\text {sed }} H^{\text {sed }}+\delta \rho^{\mathrm{Cry}} H^{\mathrm{Cry}},
$$

and $\delta \rho^{\text {sed }}$ and $H^{\text {sed }}$ are the density contrast from a reference value of $\rho_{\mathrm{c}}=2670 \mathrm{~kg} \mathrm{~m}^{-3}$ and thickness of the sediment layer, $\delta \rho^{\text {Cry }}$ and $H^{\text {Cry }}$ are the corresponding quantities for the crystalline crustal layer. The density distribution function $\bar{\rho}$ within the topography and bathymetry is defined as

$$
\bar{\rho}=\left\{\begin{array}{l}
\rho_{\mathrm{c}} \quad H \geq 0 \\
\rho_{\mathrm{c}}-\rho_{\mathrm{w}} \quad H<0
\end{array},\right.
$$

and $H$ is the topographic/bathymetric height, $\rho_{\mathrm{c}}=2670 \mathrm{~kg} \mathrm{~m}^{-3}$ is the density of the topographic 
masses, and $\rho_{\mathrm{w}}=1000 \mathrm{~kg} \mathrm{~m}^{-3}$ is the seawater density.

In Eq. (3) $C_{n}$ is the degree dependent compensation given by (Turcotte et al. 1981; Eshagh 2016b):

$C_{n}=\frac{\kappa_{n}-(1-v)}{\left(\kappa_{n}^{3}-4 \kappa_{n}^{2}\right) \frac{D}{R^{4} g}+\frac{E e_{e}}{R^{2} g}\left(\kappa_{n}-2\right)+\left(\kappa_{n}-(1-v)\right) \Delta \rho}$,

where $\kappa_{n}=\mathrm{n}(\mathrm{n}+1), g$ is the gravity and $D$ represents the flexural rigidity:

$$
D=\frac{E T_{\mathrm{e}}^{3}}{12\left(1-v^{2}\right)},
$$

$E$ is the Young modulus, $v$ is the Poisson ratio. $E, v$, $T_{\mathrm{e}}$ and $D$ are mechanical parameters of the lithosphere.

\section{Elastic Thickness According to VMM and Flexural Theories}

Here, our assumption is that the Moho variation derived from the VMM and the flexural methods are equal. In this case, according to Eqs. (1) and (3), we can write $\Delta T^{\mathrm{VMM}}=\Delta T^{\text {Flex }}$, or

$$
\begin{aligned}
C_{n}(\bar{K})_{n m}= & \frac{1}{4 \pi G \Delta \rho}\left(\frac{2 n+1}{n+1}\right) \\
& \times \beta_{n}\left(\delta g_{n m}^{\mathrm{TB}}+\delta g_{n m}^{\mathrm{Sed}}+\delta g_{n m}^{\mathrm{Cry}}-\delta g_{n m}\right) .
\end{aligned}
$$

The right hand side of Eq. (8) contains the gravity disturbances $(\delta g)$ and the effects of topography/bathymetry, sediment and crustal crystalline masses on it. The densities and thicknesses of sediment and crystalline layers are given in the CRUST1.0 model. Their gravitational potentials in terms of spherical harmonics are formulated and applied for computing their effects on the gravity disturbance. On the left hand side, are the same corresponding masses and thicknesses but instead of $\delta g$ the mechanical properties as well as $T_{\mathrm{e}}$ of the lithosphere are involved via $C_{n}$. Equation (8) is the core mathematical model for determination of $T_{\mathrm{e}}$. Now, we develop this model further by separating the term containing $\delta g_{n m}$ and rearranging the formula:

$$
\begin{aligned}
& C_{n}(\bar{K})_{n m}-\frac{1}{4 \pi G \Delta \rho}\left(\frac{2 n+1}{n+1}\right) \beta_{n}\left(\delta g_{n m}^{\mathrm{TB}}+\delta g_{n m}^{\mathrm{Sed}}+\delta g_{n m}^{\mathrm{Cry}}\right) \\
& =-\frac{1}{4 \pi G \Delta \rho}\left(\frac{2 n+1}{n+1}\right) \beta_{n} \delta g_{n m} .
\end{aligned}
$$

The goal for presenting Eq. (9) is that the Moho flexure based on the flexural and VMM isostatic methods can be used for estimating $\delta g_{n m}$, which is in fact a gravimetric quantity. However, it is well known that (Heiskanen and Moritz 1967, p. 88):

$$
\delta g_{n m}=\frac{n+1}{R} V_{n m},
$$

where $V_{n m}$ stands for the spherical harmonic coefficients of the disturbing gravitational potential. According to Eq. (10), Eq. (9) can be rewritten:

$$
\begin{aligned}
& C_{n}(\bar{K})_{n m}-\frac{2 n+1}{4 \pi G R \Delta \rho} \beta_{n}\left(V_{n m}^{\mathrm{TB}}+V_{n m}^{\mathrm{Sed}}+V_{n m}^{\mathrm{Cry}}\right) \\
& =-\frac{2 n+1}{4 \pi G R \Delta \rho} \beta_{n} V_{n m} .
\end{aligned}
$$

$V_{n m}^{\mathrm{TB}}, V_{n m}^{\mathrm{Sed}}$ and $V_{n m}^{\mathrm{Cry}}$ are, respectively, the spherical harmonics of the potential of the topographic/bathymetric masses, and those of sediments and crystalline corrections to them.

Now, Eq. (11) is solved for $V_{n m}$ :

$$
V_{n m}=V_{n m}^{\mathrm{TB}}+V_{n m}^{\mathrm{Sed}}+V_{n m}^{\mathrm{Crys}}-\frac{4 \pi G R \Delta \rho}{(2 n+1) \beta_{n}} C_{n}(\bar{K})_{n m} .
$$

Equation (12) is a mathematical model connecting the lithospheric mechanical properties to the disturbing gravitational potential. However, the GOCE data are the second-order radial derivatives of the Earth's gravitational potential. After subtracting the gravitational gradients generated by normal gravitational potential from the real ones, the secondorder derivative of the disturbing gravitational potential are obtained. The spherical harmonic expansion of this gradient is:

$V_{z z}=\frac{1}{R^{2}} \sum_{n=0}^{\infty}(n+1)(n+2)\left(\frac{R}{r}\right)^{n+3} \sum_{m=-n}^{n} V_{n m} Y_{n m}(\theta, \lambda)$.

In Eq. (13) $r$ is the geocentric radius of the satellite.

By inserting $V_{n m}$ computed from Eq. (12), containing the mechanical properties of lithosphere, the 
gravitational gradients can be synthesised on the GOCE orbit. By comparing the synthesised and real data of GOCE, we can find which $T_{\mathrm{e}}$ value should be used in Eq. (12) to achieve the closest synthesised gradient to that of the real GOCE data. This is the main principle of our method, which is a forward computational process. It should be emphasised that the synthesised GOCE data solely come from the lithosphere and the contributions from sub-lithospheric signals are absent there. This issue will be discussed later.

\section{Numerical Experiments}

Theoretical models derived in Sect. 3 are applied here to determine $T_{\mathrm{e}}$ of the lithosphere from the GOCE on-orbit vertical gravitational gradients. First, we introduce the area of interest, data acquisition is described afterwards and the results at the end.

\subsection{Study Area}

Our area of interest is Africa, bounded by the parallels $\varphi \in\left[-36^{\circ} ; 40^{\circ}\right]$ and the meridians $\lambda \in\left[-20^{\circ} ; 55^{\circ}\right]$. The topographic heights and bathymetric depths of the area, derived from DTM2006 (Pavlis et al. 2007) up to the maximum degree 2160, are plotted in Fig. 1. This map shows that the higher lands lie to the eastern and southern parts of Africa.

\subsection{Data Acquisition}

The GOCE data and the seismic CRUST1.0 model (Laske et al. 2013), from which the density, Young's modulus, Poisson ratios of the upper mantle, and the information about sediments and crustal crystalline masses are taken, are two main sources of information in this study. In the following, the GOCE data and some necessary preparation processes on them are presented.

\subsubsection{GOCE Data}

In our numerical experiments, we used the GOCE Level 2 EGG_TRF_2 data product (Gruber et al. 2010) from 4 August 2013 to 30 September 2013, i.e.,

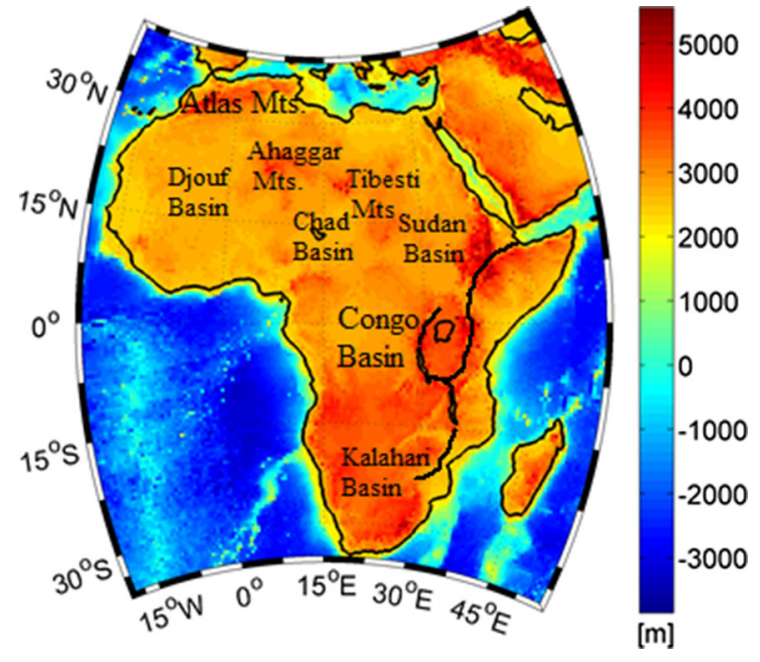

Figure 1

Topographic heights and bathymetric depths of Africa from DTM2006 digital elevation model synthesised up to degree and order 2160

approximately 2 months. This data product contains satellite gravitational gradients in the Local NorthOriented Frame (LNOF, Gruber et al. 2010). The EGG_TRF_2 data with flags higher than 2 were removed from our processing. The 403,301 data are measured during these two months over the study area for each elements of gravitational tensor. Here, we decided to apply a $10 \mathrm{~s}$ data-sampling interval and use only the vertical gravitational gradient of geopotential $V_{\mathrm{zz}}$ out of all elements of this tensor. This corresponds to 38,959 measurements of each component of the gravitational tensor. The long wavelength portion, from degree 0 to 16 (see Stewart and Watts 1997), of the gradiometric data, which comes mainly from the deep mantle is estimated from TIM-r5 (Brockmann et al. 2014) and subtracted from the GOCE data. The maps of such on-orbit GOCE vertical gravitational gradients $V_{z z}$ are presented in Fig. 2.

\subsubsection{CRUST1.0}

In order to use the flexural isostasy, the Poisson ratio and the Young modulus are required. These parameters can be computed from the $\mathrm{P}$ and $\mathrm{S}$ wave models presented in CRUST1.0. A MATLAB code has been provided by Mikael Bevis at the homepage of this model for computing these parameters. The variable 


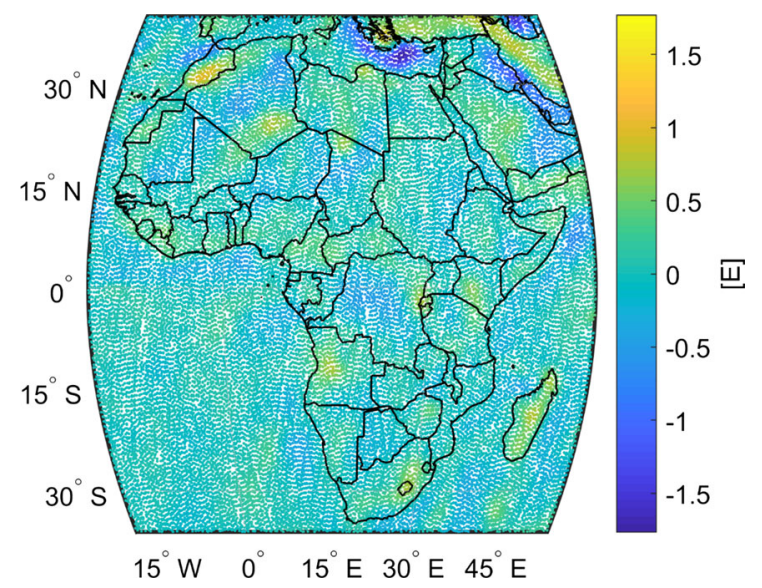

Figure 2

Regional maps of the $V_{\mathrm{zz}}$ GOCE gravitational gradients after removing the degrees $0-16$ from GGM TIM-r5

Moho depth of CRUST1.0 is plotted in Fig. 3a, showing that it reaches to a maximum value of $48 \mathrm{~km}$ located in the middle part of Sahara and in the south part of the continent in the Kalahari Deserts. The minimum values are about $15 \mathrm{~km}$ in the Red Sea. The mean value of the Moho depth $T_{0}$ over the African continent, which is needed in Eq. (3), is $37.4 \mathrm{~km}$ according to this Moho model.

Figure $3 \mathrm{a}$ is the map of seismic Moho depth of CRUST1.0. If we accept that the continent is in isostatic equilibrium, we should observe high values under the Ahaggar Mountains and the mountainous areas in the southern part of the continent. The map shows a deep Moho over Ethiopian high lands, whilst we already know the Moho surface cannot be that deep beneath the Afar hotspot. This is seen in Fig. $3 b$ showing the map of the upper mantle density. As expected, less dense materials are located along the tectonic boundaries and Gulf of Aden. The density is higher around the Congo Basin and extends southwards along the continents. It is about $3200 \mathrm{~kg} \mathrm{~m}^{-3}$ over the Afar hotspot and less than the density of surrounding areas. Figure $3 \mathrm{c}, \mathrm{d}$ are the maps of Poisson's ratio and Young's modulus, respectively, computed from the seismic waves and the upper mantle density. They have very similar patterns and the former ranges from $120 \mathrm{GPa}$ to $185 \mathrm{GPa}$, but the latter from 0.273 to 0.279 .

Here, the effects of topographic/bathymetric, density variations of sediment and crustal crystalline masses on the on-orbit $V_{\mathrm{zz}}$ are presented in Fig. 4. Topographic/bathymetric effects ranges from $-4 \mathrm{E}$ to $4 \mathrm{E}$ with positive values over the mountainous regions. The negative values are located mainly over oceans and seas. Figure $4 b$ is the effect of density variation of the sediment masses from a reference value of $2670 \mathrm{~kg} \mathrm{~m}^{-3}$, which ranges from $-2 \mathrm{E}$ to 1 E. The negative values are seen along the coastal lines and the passive continental margins. In addition, some effects are seen over the continental part over Congo, Djouf and Kalahari basins. Figure 4c shows the map of the density variation of crustal crystalline masses from the reference value, as we observe they ranges from $-1.5 \mathrm{E}$ to about $3 \mathrm{E}$.

\subsection{The Effective Elastic Thickness from GOCE Data}

The methodology of estimating the effective $T_{\mathrm{e}}$ from the GOCE satellite measurements is rather simple. At the first step, we prepared the GOCE gravitational gradients as described in Sect. 4.2.1. In the second step, different values of $T_{\mathrm{e}}$, ranging from 0 to $110 \mathrm{~km}$ with the step $1 \mathrm{~km}$, are inserted into the VMM and flexural theories Eqs. (8-13) with variable mechanical parameters of the upper mantle at each measurement point to regenerate the 38,959 GOCE data. The third step is based on finding the local minima of the absolute values of differences between the gradients generated according to the VMM and flexural theories for the each value of $T_{\mathrm{e}}$ and the GOCE data reduced for the long-wavelength. An ideal case of finding the local minima of such function for $V_{\mathrm{zz}}$ is plotted in Fig. 5a. The problem is that the local minima may not exist; see Fig. 5b, and it is not clear whether the real value of $T_{\mathrm{e}}$ at this point is zero. In some cases, this absolute difference decays monotonically, meaning that by increasing the value of $T_{\mathrm{e}}$ the difference becomes smaller. Therefore, some a priori information about the range of $T_{\mathrm{e}}$ is required to limit the maximum value of $T_{\mathrm{e}}$ in our search technique.

After estimation of $T_{\mathrm{e}}$ for each point along the satellite ground track, a moving average filer was applied to smooth the $T_{\mathrm{e}}$ model and reduce noise. Here, we used a window of $5^{\circ} \times 5^{\circ}$ and took the 

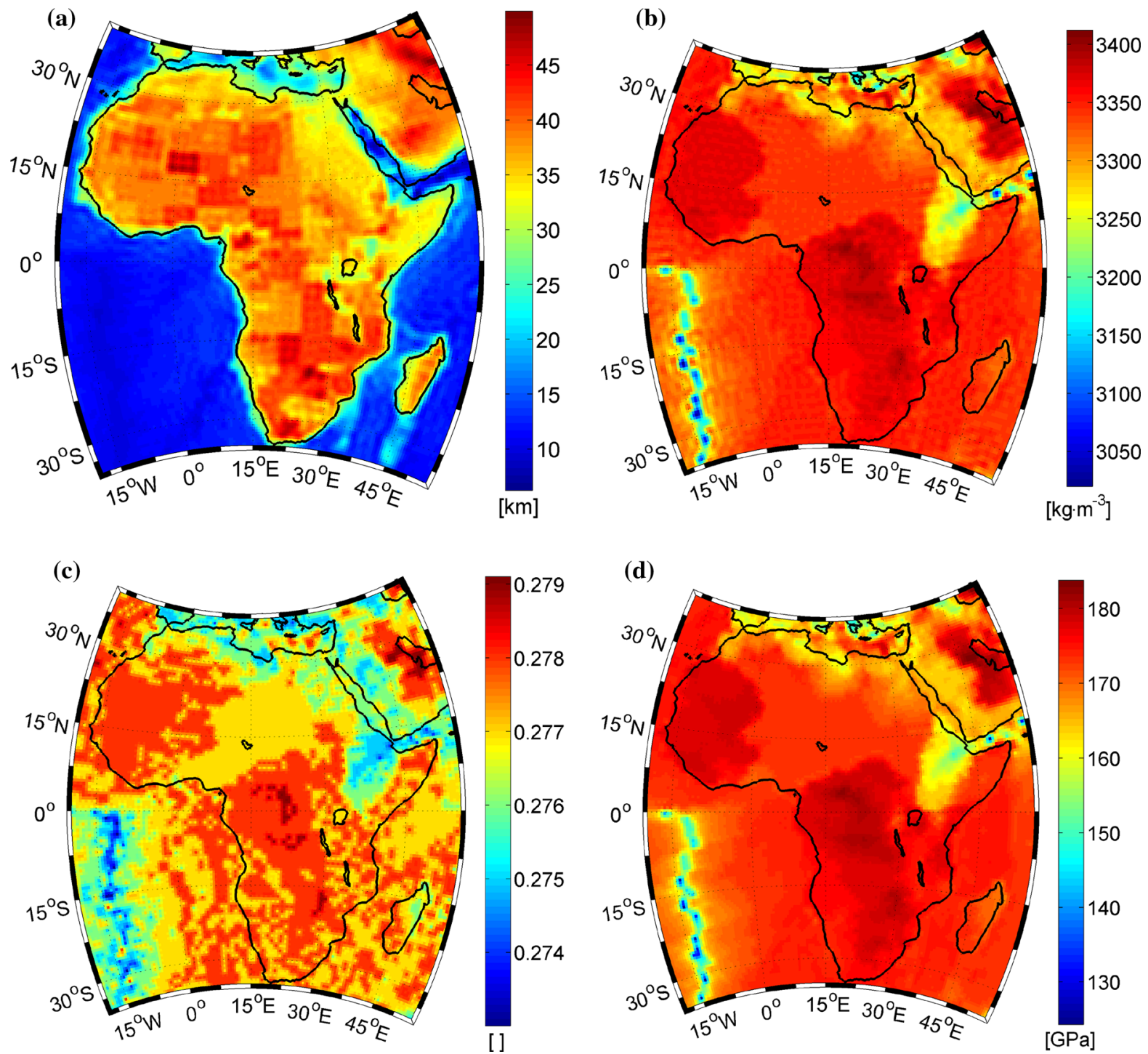

Figure 3

a The Moho depth, $\mathbf{b}$ the upper mantle density, $\mathbf{c}$ the Poisson ratio and $\mathbf{d}$ the Young modulus over Africa according to CRUST1.0

average over this window. Figure 6 is the map of the smoothed $T_{\mathrm{e}}$ model.

Our $T_{\mathrm{e}}$ map is rather smooth because of using satellite data. From the positive side, such data has uniform coverage and quality over the study area compared to spatially-limited terrestrial gravimetric data. From the isostatic prospective and flexure theory, if the lithospheric shell is thinner, it flexes more and vice versa. According to the Vening Meinesz principle, the compensation is regional, and this means that the lithospheric thickness will act as a filter to remove high frequencies of loads and give a smooth solution for the Moho interface. Therefore, it might be problematic to consider terrestrial data and topographic heights with high spatial resolutions solely. This may cause the uncertainties in the data to lead to unrealistic values for the estimated $T_{\mathrm{e}}$. Turcotte and Schubert (2014, p. 252) mentioned that the loads with shorter wavelength than $100 \mathrm{~km}$ are not compensated. This is equivalent to the spherical harmonic series limited to degree and order 180 . Therefore, the idea of considering only 

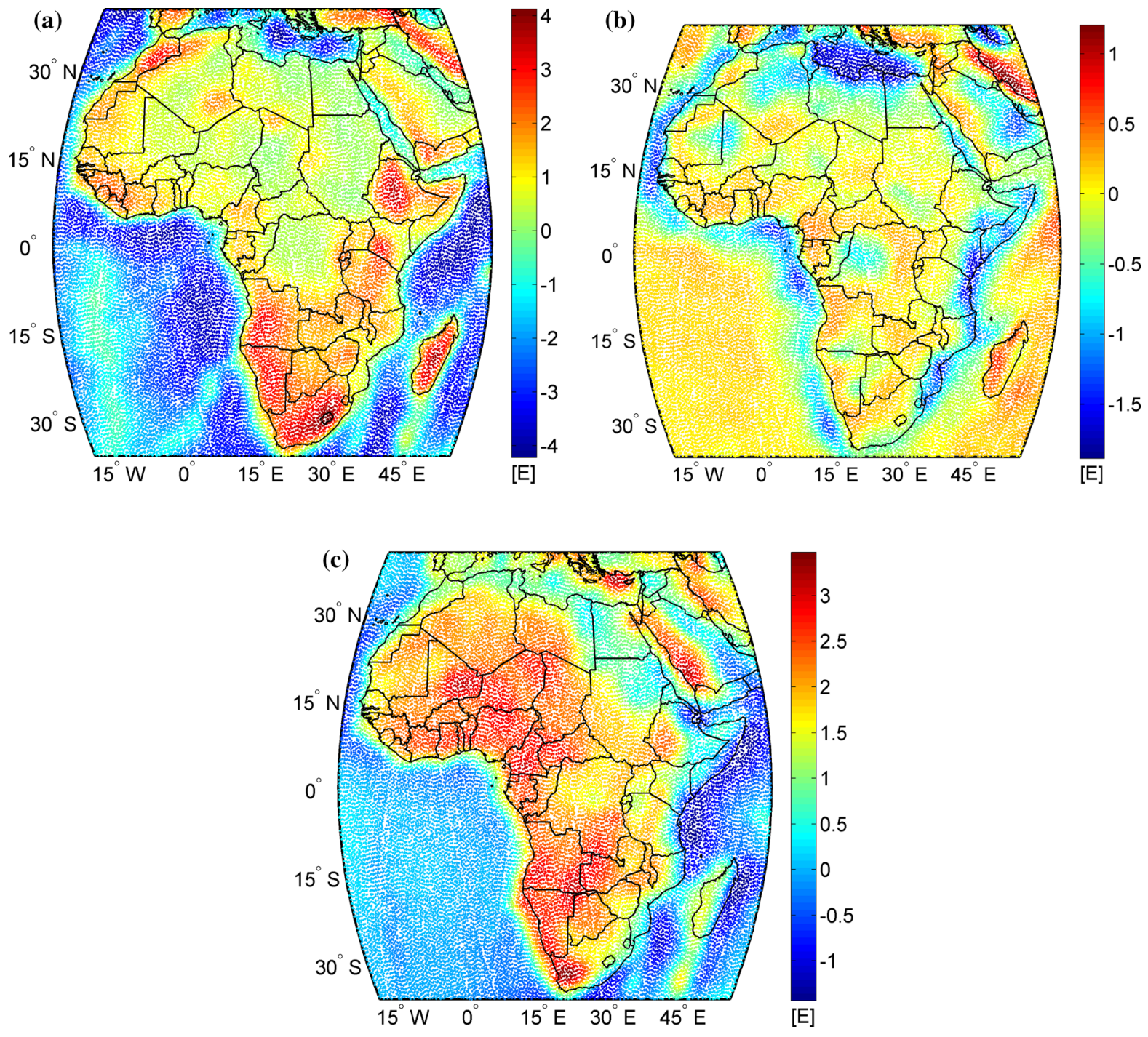

Figure 4

The effects of a topography and bathymetry, density variation from a reference density of $2670 \mathrm{~kg} \mathrm{~m}^{-3}$ of b sediments, and c crustal crystalline masses on $V_{\mathrm{zz}}$

shorter wavelengths may not result in a realistic solution for $T_{\mathrm{e}}$.

Figure 6 shows the map of $T_{\mathrm{e}}$ estimated by the proposed method over Africa. Generally, we estimated large values of $T_{\mathrm{e}}$ over Congo, Chad and Djouf cratonic basins and low values over the mountainous areas of Ahaggar, Tibesti Ethiopian high lands, volcanic areas as well as the Afar hotspot and the east African rift system. The cratonic areas are associated with high $T_{\mathrm{e}}$ (Ebinger and Sleep 1998; Pérez-Gussinyé and Watts 2005), which is consistent with the low heat flow and fast seismic velocities measured at great depths over these areas (PérezGussinyé et al. 2009). As in Fig. 4a, the map of topographic effect on the gradients, shows this effect is rather small over these areas. In addition, it is large over mountains, leading to smaller values of $T_{\mathrm{e}}$. Pérez-Gussinyé et al. (2009) also mentioned the large values over cratonic areas are consistent with the expectation for a modern rather than fossil thermal land compositional state, and this is the reason for similarity of $T_{\mathrm{e}}$ maps over continents to shear wave 

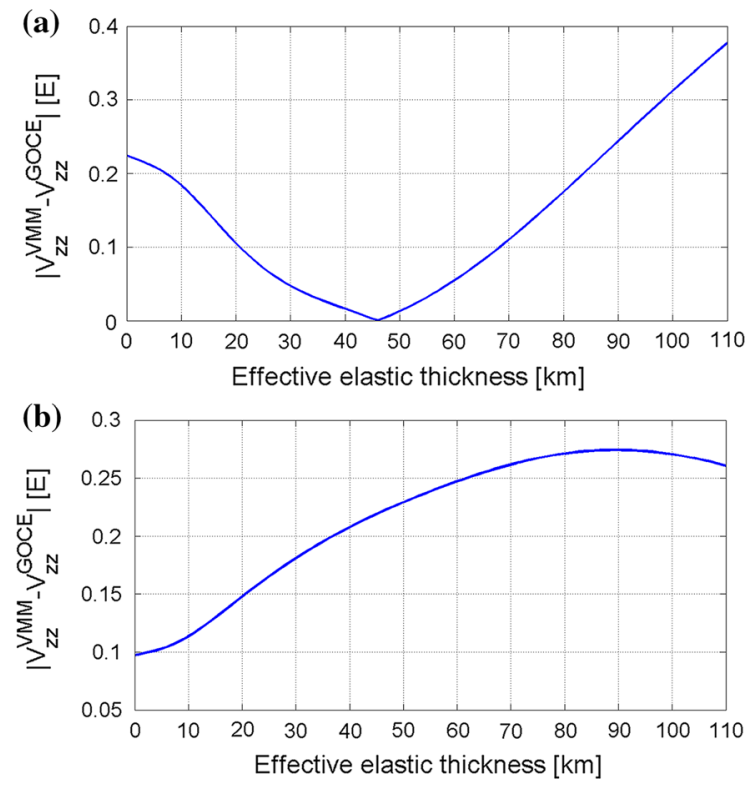

Figure 5

Ideal (a) and non-ideal (b) examples of finding the effective elastic thickness as a local minima of absolute difference between the gravitational gradients generated according to the Vening Meinesz-

Moritz theory and directly measured by the GOCE satellite

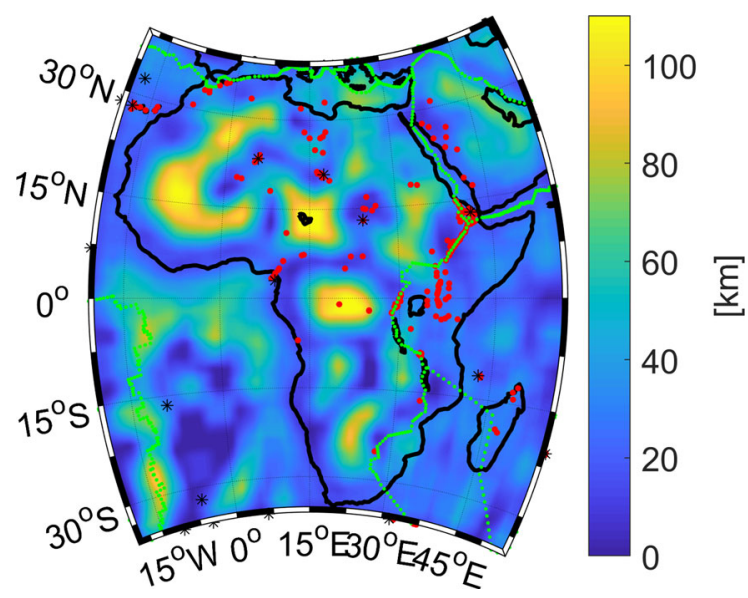

Figure 6

Map of $T_{\mathrm{e}}$ as a background for the tectonic borders visualised by green dots, volcanoes by red dots and hotspots by black asterisks

velocity maps reflecting a modern-day lithospheric property.

Pérez-Gussinyé et al. (2009) obtained large $T_{\mathrm{e}}$ in the Canaries islands and mentioned that this reflects differences between the CRUST2.0 model density structure and actual ones. However, in our map, $T_{\mathrm{e}}$ is not that large there as we used CRUST1.0, which is an updated version of CRUST2.0. However, this area is volcanic and contains a hotspot, therefore, it is expected that $T_{\mathrm{e}}$ should be very small here as our model illustrates.

On the eastern part of Ethiopia, Pérez-Gussinyé et al. (2009) obtained a high value for $T_{\mathrm{e}}$, but we cannot find any reason to have that large a value. According to Fig. 4b, c, the sediments and consolidated crystalline corrections are large over that area. Therefore, it could be due to low quality of the density structure used in CRUST2.0 in their solution. Pérez-Gussinyé et al. (2009) showed that $T_{\mathrm{e}}$ is indeterminately large all over western Africa, but our map shows small values over the Djouf cratonic basin as continuation of the Ahaggar Mountains, which is not seen in their map. The map of consolidated crystalline corrections, Fig. 4c, shows large values in this area, which causes $T_{\mathrm{e}}$ to become smaller. In addition, there are volcanoes over this area.

Over the oceans, we observe large values of $T_{\mathrm{e}}$ along the tectonic boundary between African and Nazca plates, which cannot be true and this could be due to the lack information along this boundary in the CRUST1.0 model. The St. Helena hotspot and Tristan hotspots are clear with small values of $T_{\mathrm{e}}$. Along the coastal lines, we observe oceanic basins, which are associated by larger values of $T_{\mathrm{e}}$. In the eastern oceanic part, the Comores hotspot is clearly visible by low $T_{\mathrm{e}}$; in the northern part of this area, we confirm the large values of $T_{\mathrm{e}}$ found by Peréz-Gussinye et al. (2009), although with smaller values.

According to Ebinger and Sleep (1998) the intra-continental hotspots such as Hoggar, Tibesti, Darfur and Cameron line, represent small-scale convective instabilities arising at the shaper transitions between the very thick craton lithosphere in the Congo and Western African cratons. Corridors of relatively low $T_{\mathrm{e}}$ connect these areas to each other and to the western Ethiopian plateau, related to weakening by heat advected by magmatism. Pérez-Gussinyé et al. (2009) suggest that beneath these corridors there are potential conduits for hot asthenosphere material to flow from the western Ethiopian plateau to the volcanic provinces in the central and west Africa. 


\section{Conclusions}

We have developed a forward computation method based on a combination of Vening MeineszMoritz and flexural theories of isostasy for $T_{\mathrm{e}} \bmod -$ elling from the on-orbit GOCE data. Our method works in the spatial domain and in a scatter points mode, without gridding or smoothing the measured on-orbit gradients and using any planar approximation. The principle is that the gravity gradients generated from the combination of these isostasy theories should be close to those measured by GOCE but reduced for the long wavelength structure of the gravity field. We have considered the absolute values of the differences between the generated and reduced gradients and determine for which $T_{\mathrm{e}}$ this difference is minimum. However, the problem is that this local minimum may not exist for all points. In this case, either the elastic thickness comes out very large and close to the upper bound of the search interval or very small and close to the lower bound. The use of a moving average filter for smoothing these unwanted values is recommended. Our $T_{\mathrm{e}}$ map over Africa shows large values of $T_{\mathrm{e}}$ over the cratonic basins of Congo, Chad and Djouf. Distribution of the volcanoes has a good correlation with the low $T_{\mathrm{e}}$ over the areas. In the western, central to south Africa these hotspots are connected by corridors of low $T_{\mathrm{e}}$ values connecting to the western Ethiopian plateau, which is an active system.

\section{Acknowledgements}

The authors are thankful to Professor Michal Bevis at the Ohio State University for proving the Matlab codes, and for generating the mechanical parameters of the CRUST1.0 model. Martin Pitoňák was supported by the project no. GA18-06943S of the Czech Science Foundation. Professor Carla Braitenberg and her reviewers are appreciated for their useful and constructive comments.

Open Access This article is distributed under the terms of the Creative Commons Attribution 4.0 International License (http:// creativecommons.org/licenses/by/4.0/), which permits unrestricted use, distribution, and reproduction in any medium, provided you give appropriate credit to the original author(s) and the source, provide a link to the Creative Commons license, and indicate if changes were made.

\section{REFERENCES}

Abbaszadeh, M., Sharifi, M. A., \& Nikkhoo, M. (2013). A comparison of the estimated effective elastic thickness of the lithosphere using terrestrial and satellite-derived data in Iran. Acta Geophysica, 61, 638-648.

Airy, G. B. (1855). On the computations of the effect of the attraction of the mountain masses as disturbing the apparent astronomical latitude of stations in geodetic surveys. Philosophical Transactions of the Royal Society of London, 145, 101-104.

Audet, P., \& Mareschal, J. C. (2004). Variations in elastic thickness in the Canadian shield. Earth and Planetary Science Letters, 226, 17-31.

Braitenberg, C., Ebbing, J., \& Götze, H. J. (2002). Inverse modelling of elastic thickness by convolution method-the eastern Apls as a case example. Earth and Planetary Science Letters, 202, 387-404.

Brockmann, J. M., Zehentner, N., Höck, E., Pail, R., Loth, I., Mayer-Gürr, T., et al. (2014). EGM TIM RL05: An independent geoid with centimeter accuracy purely based on the GOCE mission. Geophysical Research Letters, 41, 8089-8099.

Burov, E. B., \& Diament, M. (1995). The effective elastic thickness (Te) of continental lithosphere: what does it really mean? Journal of Geophysical Research, 100(B3), 3905-3927.

Calmant, S., Francheteau, J., \& Cazenave, A. (1990). Elastic layer thickening with age of the oceanic lithosphere: a toll for prediction of the age of volcanoes and oceanic crust. Geophysical Journal International, 100, 59-67.

Chen, B., Kaban, M. K., El Kherpy, S., \& Al-Arif, N. (2015). Effective elastic thickness of the Arabian plate: weak shield versus strong platform. Geophysical Research Letters, 42, 3298-3304.

Djomani, Y. H. P., Nnange, J. M., Diament, M., Ebinger, C. J., \& Faithead, J. D. (1995). Effective elastic thickness and crustal thickness variations in west central Africa inferred from gravity data. Journal of Geophysical Research, 100(B11), 22047-22070.

Drinkwater, M. R., Floberghagen, R., Haagmans, R., Muzi, D., \& Popescu, A. (2003). GOCE: ESA's first Earth explorer core mission. In G. B. Beutler, M. Drinkwater, R. Rummel, \& R. von Steiger (Eds.), Earth gravity field from space-from sensors to Earth sciences. In the Space Sciences Series of ISSI (Vol. 18, pp. 419-432). Dordrecht: Kluwer Academic Publisher. ISBN 1-4020-1408-2.

Ebinger, C. J., \& Sleep, N. H. (1998). Cenozoic magmatism throughout east African resulting from impact of a single plume. Nature, 395, 788-791.

Eshagh, M. (2016a). A theoretical discussion on Vening MeineszMoritz inverse problem of isostasy. Geophysical Journal International, 207, 1420-1431.

Eshagh, M. (2016b). On the Vening Meinesz-Moritz and flexural theories of Isostasy. Journal of Geodetic Science, 6, 139-151.

Eshagh, M. (2017). On the approximations in formulation of the Vening Meinesz-Moritz inverse problem of isostasy. Geophysical Journal International, 210, 500-508. 
Eshagh, M. (2018). Elastic thickness determination based on Vening Meinesz-Moritz and flexural theories of isostasy. Geophysical Journal International, 213(3), 1682-1692.

Eshagh, M., Pitonak, M., \& Tenzer, R. (2018) Lithospheric elastic thickness estimates in central Eurasia. Terrestrial, Atmospheric and Oceanic (accepted)

Filmer, P. E., McNutt, M. K., \& Wolfe, C. J. (1993). Elastic thickness of the lithosphere in the Marquesas and Society Islands. Journal of Geophysical Research, 98(B11), 19565-19577.

Forsyth, D. W. (1985). Subsurface loading and estimates of the flexural rigidity of continental lithosphere. Journal of Geophysical Research, 90, 12623-12632.

Galán, R. A., \& Casallas, I. F. (2010). Determination of effective elastic thickness of the Colombian Andes using satellite-derived gravity data. Earth Science Research Journal, 14(1), 7-16.

Gómez-Ortiz, D., Tejero, R., Ruiz, J., Babin-Vich, R., \& GonzálezCasado, J. M. (2005). Estimating the effective elastic thickness of lithosphere of the Iberian Peninsula based on multi taper spectral analysis. Geophysical Journal International, 160, 729-735.

Gruber, T., Rummel, R., Abrikosov, O., \& van Hees, R. (2010). GOCE level 2 product data handbook. Document No. GO-MAHPF-GS-0110, Issue 4, Revision 3.

Heiskanen, W. A. (1938). New isostatic tables for the reduction of the gravity values calculated on the basis of Airy's hypothesis, No. 2. Helsinki: Publications of the Isostatic Institute of the IAG.

Heiskanen, W. A., \& Moritz, H. (1967). Physical Geodesy. San Francisco: Freeman and Co.

Jeffrey, H. (1976). The earth: its origin, history and physical constitution (6th ed.). Cambridge: Cambridge University Press.

Johnsson, C. L., Solomon, S. C., Head, J. W., Phillips, R. J., Smith, D. E., \& Zuber, M. (2000). Lithospheric loading by the northern polar cap on Mars. Icarus, 144, 313-328.

Jordan, T. A., \& Watts, A. B. (2005). Gravity anomalies, flexure and the elastic thickness structure of the India-Eurasia collisional system. Earth and Planetary Science Letters, 236, 732-750.

Kalnins, L. M., \& Watts, A. B. (2009). Spatial variations on the effective elastic thickness in the western Pacific Ocean and their implications for Mesozoic volcanism. Earth and Planetary Science Letters, 286, 89-100.

Kirby, J. F. (2014). Estimation of the effective elastic thickness of the lithosphere using inverse spectral methods: The state of the art. Tectonophysics, 631, 87-116.

Laske, G., Masters, G., Ma, Z., \& Pasyanos, M. (2013). Update on CRUST1.0 - A 1-degree Global Model of Earth's Crust. In EGU General Assembly Conference Abstracts 15, 2658.

McGovern, P. J., Solomon, S. C., Smith, D. E., Zuber, M. T., Simons, M., Wieczorek, M. A., et al. (2002). Localised gravity/topography admittance and correlation spectra om Mars: Implication for regional and global evolution. Journal of Geophysical Research, 107(E-12), 5136.

McKenzie, D. (2003). Estimating $\mathrm{T}_{\mathrm{e}}$ in the presence of internal loads. Journal of Geophysical Research, 108(B9), 2438. https:// doi.org/10.1029/2002JB001766.

McKenzie, D. (2010). The influence of dynamically supported topography on estimates of $\mathrm{T}_{\mathrm{e}}$. Earth and Planetary Science Letter, 295, 127-138.

McKenzie, D., \& Fairhead, D. (1997). Estimates of the effective elastic thickness on the continental lithosphere from Bouguer and free air gravity anomalies. Journal of Geophysical Research, 102(B12), 27523-27-275235-52.

Moctar, Doucouré C., de Wit, M. J., \& Mushayandebvu, M. F. (1996). Effective elastic thickness of the continental lithosphere in South Africa. Journal of Geophysical Research, 101(B5), 11291-11303.

Moritz, H. (1990). The figure of the Earth. Karlsruhe: $\mathrm{H}$ Wichmann.

Ojeda, G., \& Whitman, D. (2002). Effect of windowing on lithosphere elastic thickness estimates obtained via coherence method: results from northern South America. Journal of Geophysical Research, 107(B11), 2275.

Pavlis, N. K., Factor, J. K., \& Holmes, S. A. (2007). Terrain-related gravimetric quantities computed for the next EGM. In: Kiliçoglu A., \& Forsberg R. (eds.): Gravity field of the earth, proceedings of the 1st International Symposium of the IGFS, Istanbul, Turkey, 318-323.

Pérez-Gussinyé, M., Lowry, A. R., \& Watts, A. B. (2007). Effective elastic thickness of South America and its implications for intracontinental deformation. Geochemistry, Geophysics, Geosystems. https://doi.org/10.1029/2006gc001511.

Pérez-Gussinyé, M., Lowry, A. R., Watts, A. B., \& Velicogna, I. (2004). On the recovery of effective elastic thickness using spectral methods, examples from synthetic data and from the Fennoscandian Shield. Journal of Geophysical Research, 109, B10409. https://doi.org/10.1029/2003JB002788.

Pérez-Gussinyé, M., Metois, M., Fernández, M., Vergéz, J., Fullea, J., \& Lowry, A. R. (2009). Effective elastic thickness of Africa and its relationship to other proxies for lithospheric structure and surface tectonics. Earth and Planetary Science Letters, 287(1-2), 152-167. https://doi.org/10.1016/j.eps1.2009.08.004.

Pérez-Gussinyé, M., \& Watts, A. B. (2005). The long term strength of Europe and its implications for plate forming processes. $\mathrm{Na}$ ture, 436, 381-384.

Sjöberg, L. E. (2009). Solving Vening Meinesz-Moritz Inverse Problem in Isostasy. Geophysical Journal International, 179, 1527-1536.

Stewart, J., \& Watts, A. B. (1997). Gravity anomalies and spatial variations of flexural rigidity at mountain ranges. Journal of Geophysical Research, 102(B3), 5327-5352.

Swain, C. J., \& Kirby, J. F. (2003a). The effect of noise on estimates of effective elastic thickness of the continental lithosphere by the coherence method. Geophysical Research Letters, 30(11), 1574.

Swain, C. J., \& Kirby, J. F. (2003b). An effective elastic thickness map of Australia from wavelet transforms of gravity and topography using Forsyth's method. Geophysical Research Letters, 33, L02314.

Tassara, A. (2005). Interaction between the Nazca and South American plates and formation of the Altiplano-Puna plateau: review of a flexural analysis along the Andean margin $\left(15^{\circ}-34^{\circ}\right.$ s). Tectonophsyics, 399, 39-57.

Tassara, A., Swain, C., Hackney, R., \& Kirby, J. (2007). Elastic thickness structure of South America estimated using wavelets and satellite-derived gravity data. Earth and Planetary Science Letters, 253, 17-36.

Tesauro, M., Kaban, M. K., \& Clotingh, S. A. P. L. (2013). Global model for the lithospheric stench and effective elastic thickens. Tectonophysics, 602, 78-86.

Tesauro, M., Kaban, M. K., Petrunin, A. G., El Kherpy, S., \& AlArifi, N. (2017). Strength and elastic thickness variations in the 
Arabian Plate: A combination of temperature, composition and strain rates of the lithosphere. Tectonophysics. https://doi.org/10. 1016/j.tecto.2017.03.004.

Turcotte, D., \& Schubert, G. (2014). Geodynamics. Cambridge: Cambridge University Press.

Turcotte, D. L., Willeman, R. J., Haxby, W. F., \& Norberry, J. (1981). Role of membrane stresses in the support of planetary topography. Journal of Geophysical Research, 86, 3951-3959.
Vening Meinesz, F. A. (1931). Une nouvelle methode pour la reduction isostatique regionale de l'intensite de la pesanteur. Bulletin Geodesique, 29, 33-51.

Watts, A. B. (2001). Isostasy and flexure of the lithosphere. New York: Cambridge University Press.

Zamani, A., Samiee, J., \& Kirby, J. F. (2014). The effective elastic thickness of the lithosphere in the collision zone between Arabia and Eurasia in Iran. Journal of Geodynamics, 81, 30-40.

(Received January 15, 2018, revised October 4, 2018, accepted October 9, 2018, Published online November 6, 2018) 